Check for updates

London, UK

Cite this as: BMJ 2021;375:n2638 http://dx.doi.org/10.1136/bmi.n2638 Published: 29 October 2021

\section{Covid-19: One in four vaccinated people living in households with a covid-19 case become infected, study finds}

\author{
Ingrid Torjesen
}

Vaccination reduces but does not eliminate the risk of covid-19 transmission within households, a study published in Lancet Infectious Diseases has found. ${ }^{1}$ It showed that one in four vaccinated household contacts of a covid-19 positive case became infected compared with $38 \%$ of unvaccinated contacts.

Transmission depends not only on the susceptibility of contacts but also on the infectivity of cases, and while vaccination reduced susceptibility of infection, it did not appear to reduce infectivity-the risk of transmission to vaccinated contacts was similar regardless of whether the index case was vaccinated or unvaccinated.

The study followed 205 household contacts of people confirmed covid-19 positive for the delta variant by polymerase chain reaction (PCR) tests and who experienced mild symptoms or were asymptomatic. Most household contacts (62\%) had been doubly vaccinated, $19 \%$ had received one vaccine dose, and $19 \%$ were unvaccinated. Contacts provided swabs for PCR testing daily for 14-20 days.

Some 53 of the 205 household contacts returned a positive PCR test during the study, including 31 of 126 who were doubly vaccinated (25\%) and 15 of the 40 unvaccinated contacts (38\%).

The median length of time since vaccination was 101 days among vaccinated contacts infected, compared with 64 days for uninfected contacts, which suggests that protection begins to wane earlier than expected, the researchers told a press conference on 28 October.

Ajit Lalvani, chair of infectious diseases, and director of the NIHR Health Protection Research Unit in Respiratory Infections, Imperial College London, said, "What we found, surprisingly, was that by three months after the second vaccine dose, the risk of acquiring infection was high compared with being more recently vaccinated. This suggests that vaccine induced protection is already waning by about three months after the second dose."

Asked whether boosters should be brought forward in light of the findings, Neil Ferguson, director of the MRC Centre for Global Infectious Disease Analysis, Imperial College London, said, "Six months is an arbitrary cut-off. It was chosen because most of the early data from Israel on the effect of boosters involve that level of delay." He added, "Biologically, there's nothing to make us think the boosters will be any less effective if given after four months. It is for the Joint Committee on Vaccination and Immunisation to consider the data and the government to consider whether they want to accelerate the booster programme."
PCR data for some of the participants was used to model their daily viral load trajectories. This revealed that viral load declined more rapidly among vaccinated people compared with those who were unvaccinated, but that there appeared to be no difference in the peak viral load of vaccinated and unvaccinated people.

"The most statistically significant data point is that vaccinated people certainly have a faster rate of viral decline," said Ferguson, "so they may potentially be infectious for less time, but they don't necessarily have any reduced peak of viral load. Most transmission probably happens around that peak of viral load, which is why we think we're still seeing substantial transmission rates from vaccinated people, both to unvaccinated people and to other vaccinated people."

Lalvani said the faster rate of decline in viral load in vaccinated people helped explain why they get fewer symptoms, quicker resolution of symptoms, and-crucially-have much lower risk of developing severe disease. The modelling showed, however, that vaccination did not affect the time people spent "in the window of highest infectiousness" during peak viral load, and only partially prevented transmission of the delta variant, he added. "This means that unvaccinated people cannot therefore rely on the immunity of the vaccinated population for protection, they remain susceptible to infection, and risk of serious illness and death.”

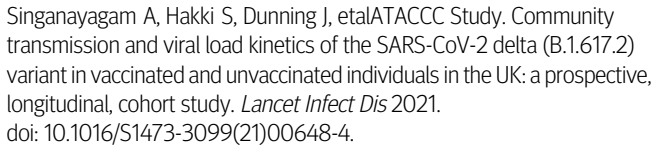
terms and conditions for the duration of the covid-19 pandemic or until otherwise determined by BMJ. You may use, download and print the article for any lawful, non-commercial purpose (including text and data mining) provided that all copyright notices and trade marks are retained.
This article is made freely available for use in accordance with BMJ's website 